ENCYCLOPEDDIE Encyclopédie berbère

BERBERE

$10 \mid 1991$

10 | Beni Isguen - Bouzeis

\title{
Bou Alem
}

G. Camps

\section{OpenEdition}

Journals

Édition électronique

URL : http://journals.openedition.org/encyclopedieberbere/1791

DOI : 10.4000/encyclopedieberbere. 1791

ISSN : 2262-7197

\section{Éditeur}

Peeters Publishers

\section{Édition imprimée}

Date de publication : 1 décembre 1991

Pagination : 1565-1568

ISBN : 2-85744-549-0

ISSN : 1015-7344

\section{Référence électronique}

G. Camps, « Bou Alem », Encyclopédie berbère [En ligne], 10 | 1991, document B91, mis en ligne le 01 juin 2013, consulté le 24 septembre 2020. URL : http://journals.openedition.org/encyclopedieberbere/ 1791 ; DOI : https://doi.org/10.4000/encyclopedieberbere.1791

Ce document a été généré automatiquement le 24 septembre 2020

(c) Tous droits réservés 


\section{Bou Alem}

\section{G. Camps}

1 Station de gravures rupestres célèbre par la représentation très réaliste d'un bélier de l'espèce Ovis longipes Fitz. Cette station est située à $3 \mathrm{~km}$ du village de Bou Alem, à proximité de la route qui rejoint Aflou à El Bayad (ex-Geryville) mais elle est encore plus proche du village d'El Ouidiane. Cette station comprend deux sites, éloignés de quelque $300 \mathrm{~m}$, tous deux en bordure de l'oued Mektouba, qui doit vraisemblablement son nom aux gravures.

2 Le premier, en arrivant de la route, est sur un pointement de grès escarpé mais très accessible, il possède principalement trois représentations d'ovins : le premier est assez schématique avec des membres exagérément allongés, caractéristique de la variété Ovis longipes; il porte sur la tête un attribut circulaire cloisonné par deux lignes verticales. Le second est dépourvu de tout ornement, et, en raison de son attitude, semble être un agneau. Le troisième est très proche de la figure du site principal, c'est un bélier à sphéroïde* sans appendice et porteur d'un collier d'épaule.

3 Le site principal figure une scène représentée en plusieurs exemplaires dans l'Atlas saharien, celle d'un bélier coiffé d'un sphéroïde précédé par un personnage en position d'orant. Ici, toutefois, la contemporanéité des deux figures fut discutée : R. Vaufrey pensait que l'homme avait été rajouté à une époque postérieure mais cette thèse ne repose que sur l'unique argument d'une différence dans le trait, celui de l'homme étant moins profond et moins poli que celui de l'animal. A cela on peut opposer d'autres observations : indépendamment du fait que cette scène est reproduite en plusieurs exemplaires (Gada el Kharrouba, Aïn Naga, Ksar el Amar, Merdoufa, Dekhet el Attech, El Hadj Mimoun...), il faut noter que l'ensemble de la scène est bien centré dans le panneau et on ne comprendrait pas que le bélier, s'il avait été seul représenté dans un premier temps, ait été cantonné dans la partie gauche. De plus, l'animal étant la victime préparée pour le sacrifice, présente plus d'importance que l'officiant, il n'est donc pas étonnant que les proportions entre les deux figures ne soient pas respectées, il en est de même à Aïn Naga, Safiat Larba, Khraloua Sadi Cheikh, ou que la gravure de l'homme soit moins soignée, comme à Merdoufa et à Mouchgueug. 

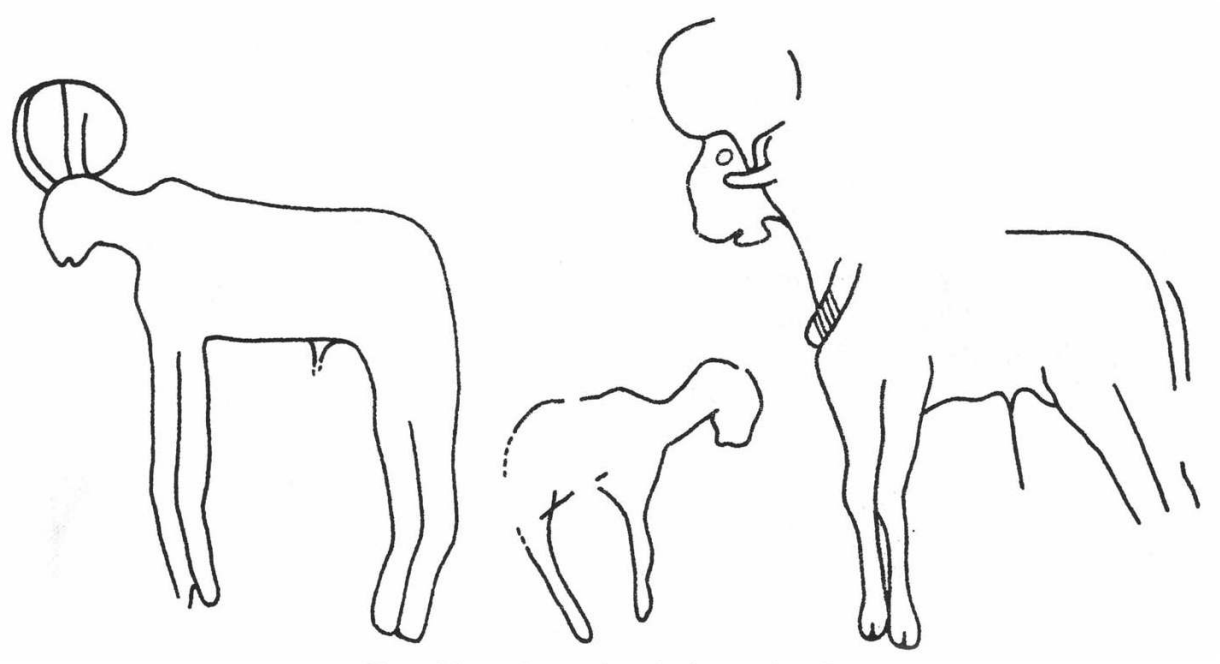

Le bélier de Bou Alem, souvent figuré seul, est la représentation la plus précise d'ovin que nous ait livrée l'art rupestre nord-africain. La gravure est extrêmement soignée et les moindres détails anatomiques indiqués avec une grande fidélité. L'érosion et la desquamation de la roche ont malheureusement fait disparaitre une partie de l'arrière train, une patte arrière jusqu'aux sabots, qui sont seuls visibles, et la queue. Le pelage, dont la longueur et l'aspect sont différents suivant les parties du corps, est particulièrement bien rendu. Moins haut sur pattes que les autres figurations d'ovins de l'Atlas saharien, le bélier de Bou Alem tout en appartenant à l'espèce Ovis longipes Fitz me parait assez proche des variétés touabir de Mauritanie et d'man de la Saoura. Comme chez tous ces ovins les cornes sont petites et retournées vers le bas et l'avant. La convexité naturelle du chanfrein a été quelque peu exagérée par l'artiste.

Les attributs culturels sont figurés avec la même précision, le "sphéroïde » est manifestement un bonnet en cuir prolongé par deux jugulaires. Deux appendices qui paraissent être des plumes plutôt que des éléments végétaux (représentés sur d'autres figures), sont piqués dans la coiffe. Le bélier de Bou Alem possède d'autres éléments de parure moins fréquents que le sphéroïde : on remarque, en premier lieu, un large collier décoré de chevrons qui suggèrent qu'il était fait en paille ou de lanières de cuir tressées. Ce collier repose sur les épaules et se prolonge, sur l'échiné, par un " caparaçon ", élément décoratif très rare puisqu'il ne se retrouve que sur un bélier de Mouchgueng (site appelé «Guelmouz el Abiod » par R. Vaufrey). Ce « caparaçon » aux bords festonnés était étroit et on ne voit pas comment il était maintenu le long de l'échine.

6 En avant du collier, le cou présente une surface glabre, limitée par un trait profond, et parfaitement polie, qui peut être comprise de deux façons, soit qu'il s'agisse d'une partie rasée en vue de l'égorgement rituel de la victime ainsi parée, soit qu'elle corresponde à une sorte de gaine de cuir souple comprimant la gorge de l'animal. 
Bou Alem, station 2 : le bélier à sphéroïde précédé par un orant.

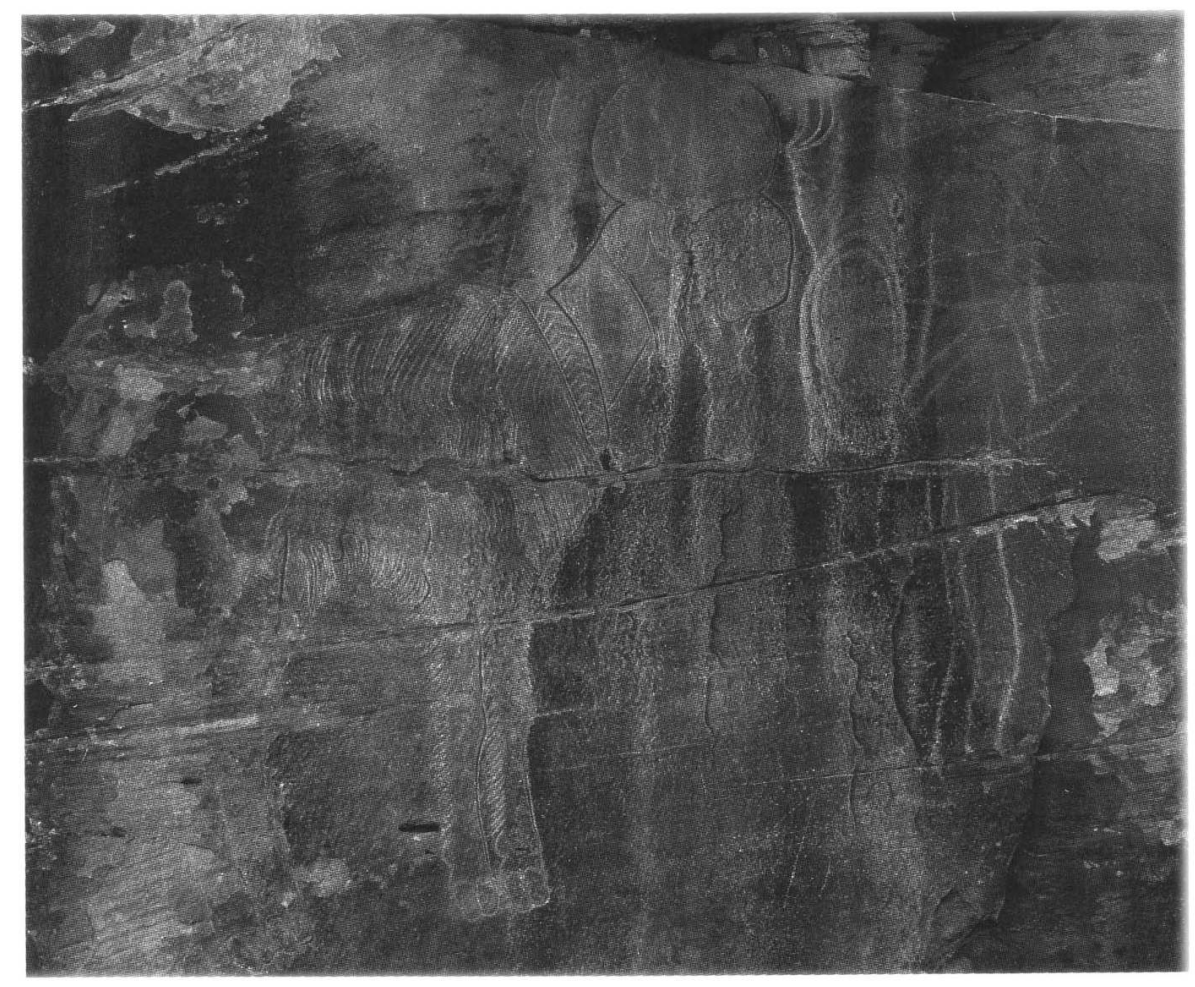

7 Nous optons pour cette deuxième explication car l'égorgement est pratiqué beaucoup plus haut, juste sous le maxillaire inférieur, région qui sur la gravure se trouve précisément en dehors de la partie polie. Il n'est pas impossible que cette gaine qui comprime le cou de l'animal ait eu pour fonction d'obliger le bélier à redresser la tête pour lutter contre un commencement d'asphyxie. Cette pratique expliquerait l'attitude anormale de ces béliers à sphéroïde dont la tête est toujours portée haut, contrairement à ce qui se passe dans la nature où les ovins ont généralement le cou horizontal. Il s'agirait, suivant notre hypothèse, d'une parure contraignante qui magnifie la victime en l'obligeant à prendre une attitude noble. Il ne peut s'agir en effet que d'une victime et non de la représentation d'une divinité. L'homme qui précède l'animal lui tourne le dos, or il a une attitude d'orant, sa dévotion ne peut s'adresser au bélier qui le suit.

8 L'orant est moins visible que le bélier mais le style est le même. Le visage, non détaillé, a un profil animal, peut-être s'agit-il d'un masque. Comme les autres personnages qui accompagnent le bélier à sphéroïde dans l'art de l'Atlas, il ne porte aucun vêtement sinon, peut-être un cache-sexe qui est parfaitement représenté à Aïn Naga, Gada el Kharrouba et Daïet es Stel. Il porte derrière le dos un objet circulaire souvent considéré comme un bouclier; cette interprétation est très discutable car le petit bouclier rond n'apparaît que dans la dernière phase de l'art rupestre atlasique, avec les cavaliers libyco-berbères. Une scène de l'oued Dermel montre un objet analogue porté de la même façon par un homme qui précède également un ovine ou un capridé porteur de collier; aussi, plutôt qu'à une arme défensive, nous songerions à une hotte ou une sacoche. A droite de la scène principale est figuré un félin, très peu visible, mais appartenant au même style. 


\section{BIBLIOGRAPHIE}

Camps G., Bélier à sphéroïde, Encyclopédie berbère, IX, 1991.

Camps G., Les civilisations préhistoriques de l'Afrique du Nordet du Sahara, Paris, Doin, 1974.

Camps G., « Un thème religieux dans l'art rupestre nord-africain. Le bélier à sphéroïde », Studi di Paletnologia in onore di Salvatore Puglisi, Rome, 1985, p. 345-357.

Curasson C, Le mouton du Soudan français, Paris, Union ovine colon. S.d.

Doutressoulle G., L'élevage du Niger, thèse pour le doctorat vétérinaire, Mortain, 1924.

Doutressoulle G., L'élevage au Soudan français, Alger, 1952.

Flamand G.B., Les Pierres écrites, Paris, Masson, 1924.

Espérandieu G., « Domestication et élevage dans le Nord de l'Afrique au Néolithique et dans la Protohistoire d'après les figurations rupestres », Actes du II Congr. panafric. de Pré-hist., Alger, 1952 (1955), p. 551-573.

Frobenius L. et Obermaier H., Hadschra Maktouba, Munich, Wolff, 1925.

Joleaud L., « Gravures rupestres et rites de l'eau », Journ. de la Soc. des Africanistes, t. III, 1933, p. 197-282 et t. IV, 1934, p. 285-302.

Lhote H., Les gravures rupestres du Sud-Oranais, C.R.A.P.E., XVI, Paris, AMG, 1970.

Libmann P., Le mouton dans les gravures et les peintures rupestres de l'Afrique du Nord et du Sahara, thèse pour le doctorat vétérinaire, Toulouse, 1979.

Vaufrey R., L'art rupestre nord-africain, Institut de Paléont. humaine, 20, 1939.

\section{INDEX}

Mots-clés : Algérie, Art rupestre 